\title{
Cost of neonatal intensive care for extremely preterm infants in Canada
}

\author{
Asaph Rolnitsky^, Sharon L. Unger, David R. Urbach^, Chaim M. Bell^ \\ University of Toronto, Toronto, Ontario, Canada \\ Contributions: (I) Conception and design: A Rolnitsky, CM Bell; (II) Administrative support: A Rolnitsky, CM Bell; (III) Provision of study materials \\ or patients: A Rolnitsky, CM Bell; (IV) Collection and assembly of data: A Rolnitsky, SL Unger, DR Urbach; (V) Data analysis and interpretation: All \\ authors; (VI) Manuscript writing: All authors; (VII) Final approval of manuscript: All authors. \\ Correspondence to: Asaph Rolnitsky, MSc, MD. Assistant Professor, University of Toronto, Staff Neonatologist, Sunnybrook Health Sciences Centre, \\ Toronto, Ontario, Canada. Email: asaph.rolnitsky@sunnybrook.ca.
}

\begin{abstract}
Background: Neonatal intensive care is expensive and prolonged. Extremely preterm infants are routinely supported. The costs for this practice at the age of borderline viability are of interest to clinicians and policymakers.

Methods: We analyzed data from the Canadian national administrative database on total cost and length of hospital care from a public payor perspective for 23-28-week premature infants from 2011 to 2015. We also compared total and daily costs for 23-25-week newborns. Each comparison evaluated the total cohort and infants who lived more than 3 days. We used non-parametric tests, correlation tests, and generalized linear models for cost difference analysis, adjusting for survival, length of stay, and year.

Results: We analyzed 6,932 infants' cost records. For all infants, median length of hospital stay was 41 days (IQR, 1-77 days). For infants who survived the first 3 days, median length of stay was 61 days (IQR, 34-90 days). The median total cost was $\$ 66,669$ (IQR, $\$ 4,920-\$ 125,550)$ ). For infants who survived the first 3 days, median total cost was $\$ 91,137$ (IQR, \$56,596-\$188,757). For infants who survived the first 3 days, median total costs were $\$ 147,835$ (IQR, \$44,711-\$233,847) for 23-week infants, \$154,736 (IQR, \$61,160$\$ 248,290$ ) for 24-week infants, and \$130,317 (IQR, \$79,737-\$229,058) for 25-week infants. These amounts did not differ $(\mathrm{P}>0.7)$.

Conclusions: Total and daily costs of neonatal intensive care are high. Total cost was not different between surviving 23-25-week infants. These findings highlight the need for a funding strategy for the routine support of these fragile infants.
\end{abstract}

Keywords: Healthcare; service; cost; prematurity

Submitted Jan 27, 2021. Accepted for publication Apr 21, 2021.

doi: $10.21037 / \mathrm{tp}-21-36$

View this article at: http://dx.doi.org/10.21037/tp-21-36

\section{Introduction}

Premature birth affects almost one in ten newborns (1). Approximately one percent of newborn infants are extremely preterm, born before 29 weeks $(2,3)$. Neonatal intensive care unit (NICU) care for extremely preterm infants is long and involves prolonged ventilatory support, parenteral nutrition, and multiple medical interventions. The intensive care required for this patient group naturally translates to a high healthcare cost (4-6). As a result, extremely preterm infants account for some of the highest expenditures in hospitalized patients (7).

Of the preterm population, infants born at 23-25 weeks of gestation, sometimes referred to as micropreterm, are

^ ORCID: Asaph Rolnitsky, 0000-0002-3399-0130; David R. Urbach, 0000-0002-6476-7337; Chaim M. Bell, 0000-0002-3778-9469. 
the most vulnerable newborns and are considered at the age of borderline viability (8). These infants require the most intensive support and they are the focus of care optimization worldwide (9). In recent years it has become common practice to offer intensive care to these infants in tertiary NICUs $(8,10)$. The majority survive to discharge home (2).

Costs for providing care to extremely preterm infants, and specifically the micropremature (23-25-week) infants, have been uncertain and controversial (11-14). Understanding these costs is important for health policymakers and planners in resource allocation decisions $(15,16)$. Further, cost is considered a component of the healthcare quality aims (17). Previous work with cost effectiveness analyses (CEAs) has estimated the costeffectiveness of NICU care (18-23) but this work did not include the most recent practice of 23-25-week infants. The most recent CEA (19) demonstrated cost effectiveness of resuscitation at 23 weeks in a theoretical model from maternal-neonatal perspective. Thus, we sought to calculate and compare the cost of care for extremely premature infants by gestational age at a national level from the public payor perspective and as a secondary outcome, to compare costs at the borderline viability preterm age of 23-25 weeks. We present the following article in accordance with the MDAR reporting checklist (available at http://dx.doi. org/10.21037/tp-21-36).

\section{Methods}

\section{Data source}

We analyzed data from the Canadian Institute for Health Information database (CIHI), a national agency responsible for collecting healthcare information. CIHI data validity is confirmed in multiple studies, demonstrating a typical $98 \%$ correlation with hospital patient charts $(24,25)$. We included liveborn deliveries at gestational age of 23-28, between January $1^{\text {st }}, 2011$ and December $31^{\text {st }}, 2015$, a timeframe which represents completed, audited, quality assured-data, and that captures years when support for 23-week infants became common in NICUs across Canada. We excluded deliveries that were stillbirths or termination of pregnancies. We analyzed the cost of the initial neonatal stay from birth to discharge home or death and subcategorized the data by gestational age. We could not include the province of Quebec, as they do not submit data to CIHI, and we excluded the Canadian Territories (Yukon, Northwest, and Nunavut) and the province of Prince Edward Island due to incomplete cost data and small numbers of preterm deliveries. We used the total cost of hospitalization of each patient in the complete hospital stay from birth to discharge home or death, including all transfers, as this reflects the complete cost to the ministries of health, representing the public. CIHI costing methodology (26) is published and standardized across the Canadian provinces (27). Physician billing is not included in CIHI data as they are mostly compensated separately by provincial billing plans. Costing was adjusted for the published Canadian Healthcare Consumer Price Index (28) in Canadian dollars. The data is restricted and is restricted from general access due to data protection agreements. The study was conducted in accordance with the Declaration of Helsinki (as revised in 2013). The study was approved by the Sunnybrook Hospital Research Ethics Board and CIHI (REB\#: 485-2016). Individual consent for this database study was waived.

\section{Statistical analysis}

We calculated means, standard deviations, $95 \%$ confidence intervals (CIs), medians, and interquartile ranges (IQRs) for each gestational age group. To correct for the low cost associated with early mortality, we repeated the cost analyses for infants surviving more than 3 days. We compared groups using Mann-Whitney-Wilcoxon tests, for non-normally distributed cost data. For trends, we calculated coefficient of determination $\left(\mathrm{R}^{2}\right)$ or the Kruskal-Wallis test for variance of non-normally distributed data. For effect size, we calculated Cohen's D or Rosenthal's $r$ for non-normally distributed data. To evaluate the gestational age contribution to the cost, we performed a Gamma-fitted, outliers-eliminated generalized linear model, of daily or total cost adjusted for length of stay, survival, and year. The adjustment for survival $>3$ days was selected to correct for the early deaths that would result in lower costs overall. We calculated CIs for each coefficient, pseudo- $\mathrm{R}^{2}$ and Akaike information criterion (AIC) to assess the model's robustness. Analyses were performed in $\mathrm{R}$ statistical language $\mathrm{v} 4$ and SPSS v23.

\section{Results}

We analysed the costs for 6,932 extremely preterm infants. Table 1 details the costs and length of stay by gestational age and survival more than 3 days.

The length of stay was variable between age groups. The median length of stay was 41 days (IQR, 1-77 days) for all included patients. The median length of stay for 


\begin{tabular}{|c|c|c|c|c|c|c|c|c|c|c|c|c|c|c|c|c|c|c|}
\hline \multirow{2}{*}{$\begin{array}{l}\text { Gestational age } \\
\text { (weeks) }\end{array}$} & \multicolumn{6}{|c|}{ Total cost (\$) } & \multicolumn{6}{|c|}{ Daily cost (\$) } & \multicolumn{6}{|c|}{ Length of stay (days) } \\
\hline & $\min$ & $1 Q$ & Median & Mean & $3 Q$ & Max & $\min$ & $1 \mathrm{Q}$ & Median & Mean & $3 Q$ & $\operatorname{Max}$ & $\min$ & $1 \mathrm{Q}$ & Median & Mean & $3 Q$ & Max \\
\hline \multicolumn{19}{|l|}{ All infants } \\
\hline 23 & 949.7 & 1,571 & 2,294.2 & $45,978.8$ & $24,899.7$ & $743,359.6$ & 633 & 1,571 & 2,012 & 2,622 & 2,672 & 146,939 & 1 & 1 & 1 & 21.4 & 7 & 272 \\
\hline 25 & 1,422 & 13,366 & 97,398 & 123,043 & 215,347 & 816,337 & 722 & 1,711 & 2,186 & 2,516 & 2,827 & 94,451 & 1 & 4 & 55 & 59 & 98 & 415 \\
\hline 26 & 813 & 30,926 & 87,436 & 109,685 & 155,592 & 662,927 & 496.1 & $1,459.2$ & $1,942.5$ & $2,191.8$ & $2,619.5$ & $62,612.3$ & 1 & 13 & 56 & 56.5 & 87 & 270 \\
\hline 27 & 813 & 34,672 & 72,193 & 90,246 & 111,783 & 813,162 & 406.5 & $1,358.5$ & $1,789.3$ & $2,196.5$ & $2,415.2$ & $71,546.8$ & 1 & 19 & 48 & 49.7 & 74 & 395 \\
\hline 28 & 804.4 & 23,013 & $58,778.4$ & $71,611.5$ & $88,727.3$ & $599,894.2$ & 581.3 & $1,345.9$ & $1,653.4$ & $1,914.3$ & $2,211.8$ & $32,599.2$ & 1 & 12 & 40 & 41 & 64 & 371 \\
\hline $23-28$ & 645.3 & 4,920 & $66,668.4$ & 92,879 & $125,550.7$ & $1,577,166.2$ & 406.5 & $1,515.6$ & $1,940.3$ & $2,278.8$ & $2,619.2$ & $146,938.6$ & 1 & 1 & 41 & 48 & 77 & 1,011 \\
\hline \multicolumn{19}{|l|}{ Surviving $>3$ days } \\
\hline 23 & 10,290 & 44,711 & 147,835 & 159,830 & 233,847 & 743,360 & 633 & 1,836 & 2,381 & 2,606 & 3,142 & 7,310 & 4 & 13.75 & 71.5 & 75.05 & 123 & 272 \\
\hline 24 & 10,126 & 61,160 & 154,736 & 172,455 & 248,290 & $1,577,166$ & 695.6 & $1,792.7$ & 2,204 & 2,386 & $2,755.8$ & $7,446.1$ & 4 & 24.5 & 88 & 82.44 & 116 & 1,011 \\
\hline 25 & 9,904 & 79,737 & 130,317 & 161,120 & 229,058 & 816,337 & 722 & 1,704 & 2,038 & 2,234 & 2,643 & 6,484 & 4 & 40 & 78 & 77.48 & 108 & 415 \\
\hline 26 & 7,355 & 72,420 & 104,778 & 138,444 & 211,265 & 662,927 & 638.5 & $1,379.3$ & $1,811.4$ & $2,013.2$ & $2,417.7$ & $26,071.5$ & 4 & 46 & 70 & 71.45 & 92.75 & 270 \\
\hline 27 & 3,411 & 56,991 & 85,060 & 109,075 & 125,411 & 813,162 & 611.7 & $1,296.9$ & $1,635.3$ & $1,863.8$ & 2,185 & 13,178 & 4 & 37 & 58 & 60.37 & 79 & 395 \\
\hline 28 & 7,886 & 42,408 & 72,193 & 86,870 & 98,812 & 599,894 & 581.8 & $1,297.7$ & $1,552.7$ & $1,792.4$ & $2,001.4$ & $13,885.7$ & 4 & 27 & 49 & 49.79 & 67 & 371 \\
\hline
\end{tabular}

he micropremature (23-25 weeks) was 17 days (IQR, 1-92 days). For infants surviving more than 3 days, the median length of stay was 61 days (IQR, 61-90 days) and for micropremature infants 79 days (IQR, 4-113 days).

The median total cost of care for the entire cohort was $\$ 66,668$ (IQR, \$4,920-\$125,550). The median daily cost for the entire cohort was $\$ 1,940$ (IQR, $\$ 1,515-\$ 2,619)$. To reduce the confounding effect of infants who were too ill to survive or were not actively supported, we calculated the costs for infants who survived more than 3 days. The median total cost of care for the entire cohort who survived 3 days was $\$ 91,137$ (IQR, $\$ 56,596-\$ 188,757$ ). The median daily cost for the entire cohort who survived $>3$ days was 1,805.5 (IQR, \$1,392-\$2,419) (Figure I).

There was no trend in cost medians during the years of the study $(\mathrm{P}=0.4)$

median total cost for the micropremature infants was $\$ 44,481$ (IQR, \$2,639-\$177,501). The median daily cost for the micropremature infants was $\$ 2,179$ (IQR, $\$ 1,706-\$ 2,849)$. The median total costs of care for the micropremature infants who survived $>3$ days was $\$ 140,526$ (IQR, \$69,783-\$236,832). The median daily cost for the micropremature infants who survived $>3$ days was $\$ 2,121$ (IQR, \$1,712-\$2,755).

There was no difference between median total costs for the 23-week-\$147,835; 24-week-\$154,736; 25-week$\$ 130,317$ (Figure 2, P>0,2). The median dily costs of care for the nicrope 2 , P. The for the $\$ 2,038$.The 3 goup $\$ 2,31 ; 24$-we $-\$ 2,204,25$-weekP2,038. The 3 groups were statistically different (Figure 2 $1 \leq 0.01)$. However, the effect size was small for all $(r=0.027$ for 23-24-week comparison, $\mathrm{r}=0.12$ for $24-25$, and $\mathrm{r}=0.00$ for 23-25) 

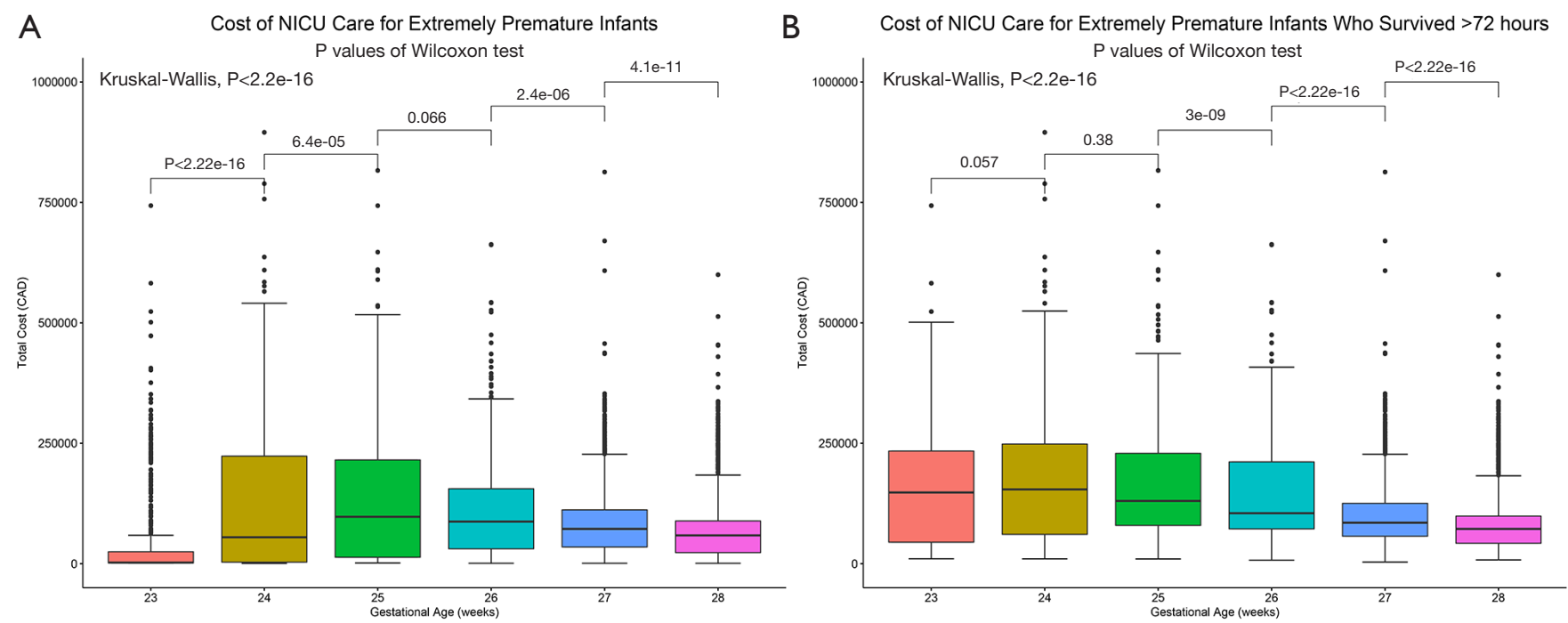

Figure 1 Cost of care for extremely premature infants by gestational age. (A) All included infants; (B) infants who survived $>3$ days.
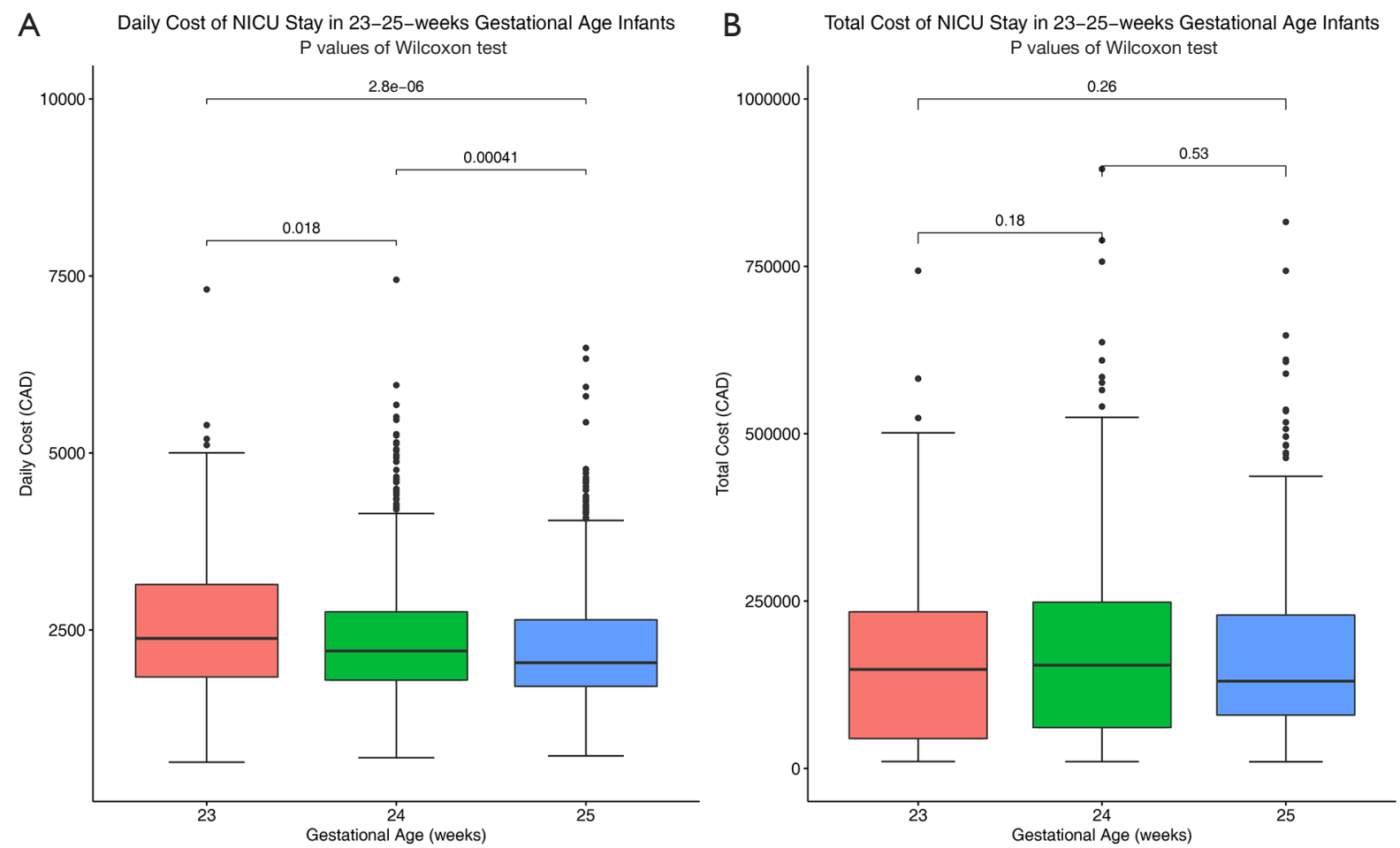

Figure 2 Cost of care for 23-25-week infants. (A) Daily cost; (B) total cost.

\section{Adjusted model}

The adjusted model for the entire cohort found that gestational age was a significant predictor of total cost when adjusted for survival over 3 days and length of stay (exponentiated coefficient estimate: $0.98,95 \%$ CI: $0.97-0.99, \mathrm{P}=0.001)$. The model was robust (pseudo- $\mathrm{R}^{2}=0.92$ ). Gestational age was a significant predictor of daily cost (exponentiated coefficient estimate: $0.92,95 \%$ CI: $0.91-0.93, \mathrm{P}<0.001)$. However, the model fit was poor (pseudo- $\mathrm{R}^{2}=0.2$ ). 
For the micropremature infants, gestational age also predicted total cost (exponentiated coefficient estimate: 1.09, 95\% CI: $1.07-1.11, \mathrm{P}<0.001)$. This model fit was robust (pseudo- $\mathrm{R}^{2}=0.95$ ). Gestational age was not a significant predictor of daily cost (exponentiated coefficient estimate: $1.014,95 \% \mathrm{CI}: 1.001-1.03, \mathrm{P}=0.07)$ but the model fit was poor (pseudo- $\mathrm{R}^{2}=0.1$ ).

\section{Discussion}

We evaluated the costs of NICU stay for extremely preterm infants of 23-28 weeks gestation at birth at a national level from a government payor perspective. We found that overall, the median daily cost of care for a very premature infant was $\$ 1,940$ (IQR, \$1,515-2,619) and did not change significantly over the study period. We also found that the median length of stay was 41 days (IQR, 1-77 days). The total costs were high: the median was $\$ 66,669$ (IQR, $\$ 4,920-\$ 125,550)$ and varied between gestational ages, increasing with lower gestational age at birth, representing more prematurity and risk of complications. For infants living more than 3 days, the median was $\$ 91,137$ (IQR, $\$ 56,596-\$ 188,575)$.

We found that in the micropremature population who survived more than 3 days, the total cost was not different between 23- and 24-week infants and the daily cost differed little. This likely reflects the difference between the lower cost for infants born at 23 weeks gestation who had low survival rates due either palliative care (leading to 1 day of admission until death) or early mortality due to extreme prematurity, and the higher survival rates in the 24-25-week population. Indeed, modelling the relationship of cost to gestational age, we found that age was a poor predictor of cost, while survival of more than 3 days was a better predictor.

Previous analyses of preterm care costing (29) have recently been published and confirm our results (29-31) of increased cost at younger ages. However, direct comparison of costing between age groups at the most extreme periviable ages was not available at the time of this analysis. Canadian funding of healthcare, a public universal healthcare coverage, is complex (32) and is comprised of federal funding, provincial funding, and other sources. In the Canadian context, and as confirmed in the other studies mentioned, the cost of neonatal care for preterm infants is very high, and is a source of interest for payors, policymakers and healthcare providers.

The strengths of our study include the use of a reliable, audited, standardized, national dataset. This source used standardized sums of the total cost of stay continuously for each patient, thereby categorizing the costs according to gestational age. As well, we were able to use recent data from time periods when infants born at 23 weeks gestation began to be supported. Further, the large number of infants born over several years helped with the comparability of our findings. Another strength is the use of "real-life" national payment validated data, that is free of any patient characteristics. Finally, we employed a validated modelling technique to adjust for important variables.

Our study has several limitations. First, some jurisdictions were not included in the analysis because of incomplete or unavailable data. Nevertheless, our data captures almost three-quarters of the national cohort. Second, cost calculations are dependent on data inputs from the various hospitals. However, CIHI implemented a standardized approach to cost calculation that has been applied to all acute care hospitals across Canada to mitigate this risk. Third, we rely on the accuracy of the CIHI data coding for several elements of our analysis. Notably, this data has been evaluated in several studies and found to be highly reproducible $(24,25)$. Fourth, our analyses only considered hospital costs from delivery through NICU, to discharge home or death. We did not include later life healthcare expenses secondary to complications related to preterm birth that are common in this cohort. Thus, this results in an underestimate of total costs but still reflects our main outcome related to NICU costs. Fifth, our study did not adjust for baseline characteristics or typical neonatal complications and outcomes. Our study was designed to describe the costs associated with extreme preterm birth in hospital care with an aim to measure the cost to the payor. A formal cost-effectiveness analysis could provide further details on cost per-outcome. Nevertheless, we can predict with the current result cost-effective NICU care as the survival of the infants is so high. Lastly, the ethical questions regarding quality of life versus resource allocation are not discussed in this study. These considerations were out of scope but undeniably important. The consideration of cost in medical care has been discussed in other studies (14,33-35). Neonatal intensive care has used this data to demonstrate cost effectiveness. We believe that an updated formal cost utility analysis informed by our data is timely and relevant. Our demonstration that even at the extreme periviable ages of 23-25 weeks gestation the cost of care is not different, may be an argument for or reassurance to continue the practice of life support for this gestational age 
group for policymaker and funding authorities.

Our findings describe the high cost of initial hospitalization for extremely preterm infants by gestational age. The cost and length of stay reflect differential survival of infants by birth age, but also underscore similarities even in the lowest age groups. The overall cost of care for extremely preterm infants is high and reflects the prolonged stay till maturity to discharge home. Our current knowledge of preterm outcomes demonstrates this cost is associated with high and increasing survival rates and a good quality of life in this population later in life (36). Our next steps would be to specifically evaluate regional differences and diagnoses that predict higher costs, thereby enabling a better understanding of neonatal morbidities as important determinants of societal spending on health.

Our study of costs for critical care of extremely premature infants underscores the notion that extremely preterm infants are not substantively different from slightly older preterm infants in their health-related costs in the neonatal period. Indeed, the advances that "push the envelope" in the care of these fragile newborns do not appear to come with markedly different costs.

\section{Acknowledgments}

Funding: None.

\section{Footnote}

Reporting Checklist: The authors have completed the MDAR reporting checklist. Available at http://dx.doi.org/10.21037/ tp-21-36

Data Sharing Statement: Available at http://dx.doi. org/10.21037/tp-21-36

Conflicts of Interest: All authors have completed the ICMJE uniform disclosure form (available at http://dx.doi. org/10.21037/tp-21-36). The authors have no conflicts of interest to declare.

Ethical Statement: The authors are accountable for all aspects of the work in ensuring that questions related to the accuracy or integrity of any part of the work are appropriately investigated and resolved. The study was conducted in accordance with the Declaration of Helsinki (as revised in 2013). The study was approved by the Sunnybrook Hospital Research Ethics Board and CIHI
(REB\#: 485-2016). Individual consent for this database study was waived.

Open Access Statement: This is an Open Access article distributed in accordance with the Creative Commons Attribution-NonCommercial-NoDerivs 4.0 International License (CC BY-NC-ND 4.0), which permits the noncommercial replication and distribution of the article with the strict proviso that no changes or edits are made and the original work is properly cited (including links to both the formal publication through the relevant DOI and the license). See: https://creativecommons.org/licenses/by-nc-nd/4.0/.

\section{References}

1. Irvine B, Dzakpasu S, León JA. Perinatal health indicators 2013: a surveillance report by the Public Health Agency of Canada's Perinatal Surveillance System. Health Promot Chronic Dis Prev Can 2015;35:23-4.

2. The Canadian Neonatal NetworkTM [Internet]. [cited 2019]. Available online: http://www. canadianneonatalnetwork.org/portal/

3. Shah PS, McDonald SD, Barrett J, et al. The Canadian Preterm Birth Network: a study protocol for improving outcomes for preterm infants and their families. CMAJ Open 2018;6:E44-9.

4. Petrou S, Khan K. Economic costs associated with moderate and late preterm birth: primary and secondary evidence. Semin Fetal Neonatal Med 2012;17:170-8.

5. Barradas DT, Wasserman MP, Daniel-Robinson L, et al. Hospital Utilization and Costs Among Preterm Infants by Payer: Nationwide Inpatient Sample, 2009. Matern Child Health J 2016;20:808-18.

6. Clements KM, Barfield WD, Ayadi MF, et al. Preterm birth-associated cost of early intervention services: an analysis by gestational age. Pediatrics 2007;119:e866-874.

7. Guilcher SJT, Bronskill SE, Guan J, et al. Who Are the High-Cost Users? A Method for Person-Centred Attribution of Health Care Spending. PLoS One 2016;11:e0149179.

8. Ladhani NNN, Chari RS, Dunn MS, et al. No. 347-Obstetric Management at Borderline Viability. J Obstet Gynaecol Can 2017;39:781-91.

9. Stoll BJ, Hansen NI, Bell EF, et al. Neonatal outcomes of extremely preterm infants from the NICHD Neonatal Research Network. Pediatrics 2010;126:443-56.

10. Jefferies AL, Kirpalani HM; Canadian Paediatric Society Fetus and Newborn Committee. Counselling and 
management for anticipated extremely preterm birth. Paediatr Child Health 2012;17:443-6.

11. Schwartz RM. What price prematurity? Fam Plann Perspect 1989;21:170-4.

12. Singer P. A report from Australia: which babies are too expensive to treat? Bioethics 1987;1:275-83.

13. Yu V. Extremely premature infants: to treat or not to treat? Bioeth News 1984;3:6-12.

14. Meadow W, Cohen-Cutler S, Spelke B, et al. The prediction and cost of futility in the NICU. Acta Paediatr 2012;101:397-402.

15. DeRienzo C, Kohler JA, Lada E, et al. Demonstrating the relationships of length of stay, cost and clinical outcomes in a simulated NICU. J Perinatol 2016;36:1128-31.

16. Diehl-Svrjcek BC, Richardson R. Decreasing NICU Costs in the managed care arena: the positive impact of collaborative high-risk OB and NICU disease management programs. Lippincotts Case Manag 2005;10:159-66.

17. Berwick DM, Nolan TW, Whittington J. The Triple Aim: Care, Health, And Cost. Health Aff (Millwood) 2008;27:759-69.

18. Rushing S, Ment LR. Preterm birth: a cost benefit analysis. Semin Perinatol 2004;28:444-50.

19. Partridge JC, Robertson KR, Rogers EE, et al. Resuscitation of neonates at 23 weeks' gestational age: a cost-effectiveness analysis. J Matern Fetal Neonatal Med 2015;28:121-30.

20. Nair PM. Survival of extreme pre-term infants in an intensive care set up. Saudi Med J 2000;21:891-2.

21. Siegel LS. The long-term prognosis of pre-term infants: conceptual, methodological, and ethical issues. Hum Nat 1994;5:103-26.

22. Hernandez JA, Offutt J, Butterfield LJ. The cost of care of the less-than-1000-gram infant. Clin Perinatol 1986;13:461-76.

23. Walker DJ, Feldman A, Vohr BR, et al. Cost-benefit analysis of neonatal intensive care for infants weighing less than 1,000 grams at birth. Pediatrics 1984;74:20-5.

24. Scales DC, Guan J, Martin CM, et al. Administrative data accurately identified intensive care unit admissions in

Cite this article as: Rolnitsky A, Unger SL, Urbach DR, Bell CM. Cost of neonatal intensive care for extremely preterm infants in Canada. Transl Pediatr 2021;10(6):1630-1636. doi: $10.21037 /$ tp-21-36
Ontario. J Clin Epidemiol 2006;59:802-7.

25. Joseph KS, Fahey J, Canadian Perinatal Surveillance System. Validation of perinatal data in the Discharge Abstract Database of the Canadian Institute for Health Information. Chronic Dis Can 2009;29:96-100.

26. Canadian Institute for Health Information. Canadian Patient Cost Database Technical Document: MIS Patient Costing Methodology, January 2019:56.

27. Canadian Institute for Health Information. Cost of a Standard Hospital Stay: Appendices to Indicator LibraryMethodology Notes, May 2020. Ottawa, ON: CIHI, 2020.

28. Statistics Canada. Add/Remove data - Consumer Price Index by product group, monthly, percentage change, not seasonally adjusted, Canada, provinces, Whitehorse, Yellowknife and Iqaluit [Internet]. 2019 [cited 2019]. Available online: https://www150.statcan.gc.ca/t1/tbl1/en/ cv.action?pid=1810000413

29. Petrou S, Yiu HH, Kwon J. Economic consequences of preterm birth: a systematic review of the recent literature (2009-2017). Arch Dis Child 2019;104:456-65.

30. Rios JD, Shah PS, Beltempo M, et al. Costs of Neonatal Intensive Care for Canadian Infants with Preterm Birth. J Pediatr 2021;229:161-167.e12.

31. Johnston KM, Gooch K, Korol E, et al. The economic burden of prematurity in Canada. BMC Pediatr 2014;14:93.

32. Martin D, Miller AP, Quesnel-Vallée A, et al. Canada's universal health-care system: achieving its potential. Lancet 2018;391:1718-35.

33. Culyer AJ. Economics and ethics in health care. J Med Ethics 2001;27:217-22.

34. Scheunemann LP, White DB. The Ethics and Reality of Rationing in Medicine. Chest 2011;140:1625-32.

35. Meadow W. Epidemiology, economics, and ethics in the NICU: reflections from 30 years of neonatology practice. J Pediatr Gastroenterol Nutr 2007;45 Suppl 3:S215-7.

36. Zwicker JG, Harris SR. Quality of Life of Formerly Preterm and Very Low Birth Weight Infants from Preschool Age to Adulthood: A Systematic Review. Pediatrics 2008;121:e366-76. 